Ligation of both TLR2 and 9 on human cells has been shown to be associated with the development of T-reg cells and/or tolerance $[5,6]$. We found that HSV infection conferred protection against atopy among Finnish children only. Besides the fact that atopy is infrequent in Russian Karelia, the overall exposure to microorganisms is overwhelming and the impact of saprophytes and other pathogens may well override the possible effects of HSV on the Russian side.

In summary, in an area with a relatively low microbial burden such as Finnish Karelia, herpes simplex virus appears to be able to exert immunomodulatory potential, which may have implications for the occurrence of atopy. This finding confirms the result shown previously in two other Western populations [7, 8].

L.C. von Hertzen*, P.T. Pekkarinen", T. Laatikainen", M.J. Mäkelä, and T. Haahtela for the Karelian Allergy Study Group

*Skin and Allergy Hospital, Helsinki University Central Hospital, and "Dept of Chronic Diseases and Health Promotion, National Public Health Institute, Helsinki, Finland.

\section{ACKNOWLEDGEMENTS}

The members of the Karelian Allergy Study Group also include: P. Jousilahti and E. Vartiainen (National Public Health Institute, Helsinki); and T.U. Kosunen (Helsinki University/Haartman Institute, Helsinki, Finland).

\section{SUPPORT STATEMENT}

This study was founded by a Helsinki University Central Hospital (Helsinki Finland) grant and a grant from the Allergy Foundation.

\section{STATEMENT OF INTEREST}

None declared.

\section{REFERENCES}

1 Mills KH. Regulatory T cells: friend or foe in immunity to infection?Nat Rev Immunol 2004; 4: 841-855.

2 Pekkarinen PT, von Hertzen L, Laatikainen T, et al. A disparity in the association of asthma, rhinitis, and eczema with allergen-specific $\operatorname{IgE}$ between Finnish and Russian Karelia Allergy 2007; 62: 281-287.

3 Suvas S, Azkur AK, Kim BS, Kumaraguru U, Rouse BT. CD4+CD25+ regulatory $\mathrm{T}$ cells control the severity of viral immunoinflammatory lesions J Immunol 2004; 172: 4123-4132.

4 Herbst-Kralovetz M, Pyles R. Toll-like receptors, innate immunity and HSV pathogenesis Herpes 2006; 13: 37-41.

5 Taylor RC, Richmond P, Upham JW. Toll-like receptor 2 ligands inhibit Th2 responses to mite allergens J Allergy Clin Immunol 2006; 117: 1148-1154.

6 Moseman EA, Liang X, Dawson AJ, et al. Human plasmacytoid dendritic cells activated by CpG oligodeoxynucleotides induce the generation of CD4+CD25+ regulatory T cells J Immunol 2004; 173: 4433-4442.

7 Matricardi PM, Rosmini F, Panetta V, Ferrigno L, Bonini S. Hay fever and asthma in relation to markers of infection in the United States J Allergy Clin Immunol 2002; 110: 381-387.

8 Illi S, von Mutius E, Lau S, et al. Early childhood infectious diseases and the development of asthma up to school age: a birth cohort study BMJ 2001; 322: 390-395.

\title{
Variation in the tumour necrosis factor gene is not associated with susceptibility to COPD
}

\section{To the Editors:}

In a recent issue of the European Respiratory Journal, TANAKA et al. [1] studied polymorphisms in the tumour necrosis factor (TNF) and lymphotoxin A genes with respect to their effect on lung function of smokers, and failed to find any association with chronic obstructive pulmonary disease (COPD) phenotypes. TANAKA et al. [1] acknowledge that their work is not a true casecontrol study, but that it would be better described as an investigation of genetic contribution to disease severity. There have been several studies of variation in TNF with respect to susceptibility to COPD, although many of these have used relatively small sample sizes and are therefore underpowered, and so are likely to lead to results that cannot be replicated.

As part of a European Union collaborative project, we have studied polymorphisms within the TNF gene in a large collection of well-characterised Caucasian COPD patients $(n=1,018)$ and control subjects $(n=911)$. COPD cases and

\begin{tabular}{|c|c|c|c|}
\hline \multirow[t]{2}{*}{ TABLE 1} & \multicolumn{3}{|c|}{$\begin{array}{l}\text { Frequency of single nucleotide polymorphisms } \\
\text { (SNPS) genotyped in the tumour necrosis factor } \\
\text { gene }\end{array}$} \\
\hline & & COPD patients & Controls \\
\hline \multicolumn{2}{|c|}{ rs1799964" (T-1031C) } & 0.207 & 0.193 \\
\hline \multicolumn{2}{|c|}{ rs $1800629^{\circ}(G-308 A)$} & 0.179 & 0.178 \\
\hline \multicolumn{2}{|c|}{ rs $361525^{\circ}(G-238 A)$} & 0.055 & 0.049 \\
\hline \multicolumn{2}{|c|}{ rs1800610 (G489A) } & 0.096 & 0.096 \\
\hline \multicolumn{2}{|c|}{ rs3093662 (A851G) } & 0.084 & 0.077 \\
\hline \multicolumn{2}{|c|}{ rs1800628 (G3512A) } & 0.127 & 0.119 \\
\hline
\end{tabular}


TABLE 2 Haplotypes of tumour necrosis factor single nucleotide polymorphisms and frequency in cases and controls

\begin{tabular}{|c|c|c|c|c|c|c|c|c|}
\hline & \multicolumn{6}{|c|}{ Polymorphism } & \multicolumn{2}{|c|}{ Frequency } \\
\hline & rs1799964 & rs1800629 & rs361525 & rs1800610 & rs3093662 & rs1800628 & Controls & COPD cases \\
\hline 1 & $\mathrm{~T}$ & A & G & $\mathrm{G}$ & A & G & 0.058 & 0.052 \\
\hline 2 & T & G & G & G & A & G & 0.502 & 0.489 \\
\hline 3 & $\mathrm{~T}$ & G & G & A & A & G & 0.095 & 0.095 \\
\hline 6 & A & G & A & $\mathrm{G}$ & $\mathrm{G}$ & G & 0.050 & 0.053 \\
\hline 7 & T & A & G & G & A & A & 0.120 & 0.127 \\
\hline Rare haplotypes & & & & & & & 0.001 & 0.002 \\
\hline
\end{tabular}

control subjects were recruited from six European centres, as previously reported [2]. The characteristics of each group are summarised as follows, with data expressed as mean $\pm \mathrm{SD}$, where appropriate. Controls: $63.5 \%$ male; age $60.8 \pm 8.9 \mathrm{yrs}$; smoking history $38.6 \pm 17.4$ pack-yrs; forced expiratory volume in one second (FEV1) $95.3 \pm 10.9 \%$ predicted; FEV1/forced vital capacity (FVC) $77.9 \pm 4.9 \%$. COPD cases: $69.6 \%$ male; age $65.8 \pm 8.2$ yrs; smoking history $48.9 \pm 23.6$ pack-yrs; FEV1 $43.0 \pm 15.3 \%$ pred; FEV1/FVC $47.5 \pm 12.2 \%$.

Six single nucleotide polymorphisms (SNPs) in TNF (table 1) were genotyped using Taqman ${ }_{\circledR}$ probes (Geneservice Ltd, Babraham, UK). Primer and probe sequences are available on request. As quality control measures for the genotyping, $2 \%$ of samples of known genotype were included and $10 \%$ of samples were present in duplicate to check for concordance. All SNPs were in Hardy-Weinberg equilibrium.

The association of single SNPs with COPD was carried out using a Chi-squared analysis; none of the SNPs showed a significant difference in genotype frequency between cases and controls $(p \geqslant 0.331)$. Linear regression analysis in cases and controls was used to identify any possible effect of TNF genotype on FEV1 (with age, smoking history and sex as covariates). Using a stringent cut-off, this also failed to find any significant effect, with the lowest p-value being obtained for rs1800628 in controls only $p=0.010$. Allowing for multiple testing, this is unlikely to be a true association.

A case-control analysis of TNF haplotypes was carried out according to [3]. Haplotypes of the TNF SNPs are shown in table 2 . This analysis identified a total of 10 haplotypes, seven of which were present at a frequency $>2 \%$. There was no significant difference in the frequency of these haplotypes between COPD cases and controls (global score statistic $=2.024$, 7 degrees of freedom; $p=0.959$ ). Similarly, using the omnibus test performed over all haplotypes in the SAS procedure PROC HAPLOTYPE [4], none of the possible subsets of the six SNPs showed a significant relationship with COPD.

In this large case-control study using well-characterised COPD patients and controls, we failed to find any association of the TNF polymorphisms with the development of COPD. This is in agreement with other smaller studies in Caucasian populations [5-8], although many studies have only considered the -308 SNP. One study, using 169 Caucasian COPD patients and 358 controls, showed an increase of the 489_GA genotype in the COPD patients with an associated odds ratio of 1.9 [9]; however, this is not replicated in the current study, suggesting that it may have been a false-positive result.

For allele frequencies ranging $0.05-0.20$ (using a dominant model and $\alpha=0.01$ ), the current study has $>80 \%$ power to detect minimum effect sizes of 1.4-1.65. The fact that we see no association with any of the tumour necrosis factor single nucleotide polymorphisms or haplotypes makes it highly unlikely that polymorphisms in this gene play a major role in the susceptibility to chronic obstructive pulmonary disease.

S. Chappell*, L. Daly", K. Morgan*, T.G. Baranes*, J. Roca", R. Rabinovich ${ }^{\uparrow}$, A. Millar ${ }^{+}$, S.C. Donnelly ${ }^{\S}$, V. Keatings ${ }^{f}$, W. MacNee**, J. Stolk"\# , P.S. Hiemstra ${ }^{\# \#, ~ M . ~ M i n i a t i ~}{ }^{* \uparrow "}$, S. Monti ${ }^{\oplus \uparrow, ~ C . M . ~ O ' C^{\prime} \text { Connor }}{ }^{\delta,++}$ and N. Kalsheker ${ }^{*,++}$

*Division of Clinical Chemistry, Molecular Medical Sciences, Institute of Genetics, University Hospital, Queens Medical Centre, University of Nottingham, Nottingham, and ${ }^{+}$Lung Research Group, Dept of Clinical Science at North Bristol, Southmead Hospital, University of Bristol, Westbury on Trym, Bristol, and ${ }^{* *}$ Respiratory Medicine, ELEGI Colt Laboratories, Wilkie Building, University of Edinburgh, Edinburgh, UK. ${ }^{\S}$ School of Medicine and Medical Science, the Conway Institute, and "School of Public Health and Population Science, University College Dublin, Belfield, Dublin, and ${ }^{f}$ Letterkenny General Hospital, Letterkenny, Donegal, Ireland. and "Pulmonary Dept, Hospital Clinic, Hospital Clínico y Provincial de Barcelona, Villarroel, Barcelona, Spain. \#\# Dept of Pulmonology (C3-P), Leiden University Medical Center, Leiden, The Netherlands. ${ }^{~ " C N R}$ Institute of Clinical Physiology, Pisa, Italy. ${ }^{++}$Joint senior authors.

\section{STATEMENT OF INTEREST}

None declared. 


\section{REFERENCES}

1 Tanaka G, Sandford AJ, Burkett K, et al. Tumour necrosis factor and lymphotoxin A polymorphisms and lung function in smokers Eur Respir J 2007; 29: 34-41.

2 Chappell S, Daly L, Morgan K, et al. Cryptic haplotypes of SERPINA1 confer susceptibility to chronic obstructive pulmonary disease Hum Mutat 2006; 27: 103-109.

3 Sinnwell JP, Schaid DJ, Yu Z. Statistical analysis of haplotypes. Version 1.2.2., http:/ / cran.r-project.org/src/contrib/ Descriptions/haplo.stats.html Date last update: June 2007.

4 SAS/Genetics User's Guide. Release 8.2. Cary, SAS Institute Inc., 2002.

5 Hersh CP, DeMeo DL, Lange C, et al. Attempted replication of reported chronic obstructive pulmonary disease candidate gene associations Am J Respir Cell Mol Biol 2005; 33: 71-78.
6 Higham MA, Pride NB, Alikhan A, Morrell NW. Tumour necrosis factor- $\alpha$ gene promoter polymorphism in chronic obstructive pulmonary disease Eur Respir J 2000; 15: 281-284.

7 Patuzzo C, Gilè LS, Zorzetto M, et al. Tumor necrosis factor gene complex in COPD and disseminated bronchiectasis Chest 2000; 117: 1353-1358.

8 Ruse CE, Hill MC, Tobin M, et al. Tumour necrosis factor gene complex polymorphisms in chronic obstructive pulmonary disease Respir Med 2007; 101: 340-344.

9 Küçükaycan M, Van Krugten M, Pennings HJ, et al. Tumor necrosis factor $\alpha+489 \mathrm{G} / \mathrm{A}$ gene polymorphism is associated with chronic obstructive pulmonary disease Respir Res 2002; 3: 29.

DOI: 10.1183/09031936.00057107

\section{Beyond the "ABC approach"}

To the Editors:

I read with interest the recent review by CELLI and BARNES [1], wherein the authors have beautifully discussed the aetiology, cellular and molecular mechanisms, management and new definition of exacerbations of chronic obstructive pulmonary disease (COPD).

In the management of acute exacerbations of COPD they have discussed the role of three classes of drugs (antibiotics, bronchodilators and corticosteroids, i.e. an "ABC approach"); however, the role of oxygen therapy, theophylline and supportive management is not mentioned. All of these have implications for the management of the disease.

Hypoxia at exacerbation of COPD is quite common and may be life threatening. The importance of controlled oxygen therapy during the management of acute exacerbation cannot be overlooked [2].

Theophylline is widely used in the management of stable patients with COPD. A recent meta-analysis evaluating the role of intravenous aminophylline in cases of acute exacerbation of COPD did not find any beneficial effect in terms of improvement of pulmonary function or symptoms [3]. However, the withdrawal of methylxanthines in patients already receiving them can worsen lung function, clinical status, exercise performance and ratings of dyspnoea [4]. Therefore, patients already receiving oral preparations of methylxanthines for stable disease should continue on such treatments at the time of exacerbation. The current Global Initiative for Chronic Obstructive Lung Disease (GOLD) guidelines even suggest adding aminophylline to standard therapy for patients with moderate-to-severe exacerbations or those not responding to nebulised short-acting bronchodilators [5].

Appropriate fluid balance (with special attention to the administration of diuretics), nutritional aspects, anticoagulants, and cardiovascular agents are the most complementary standard measures. Manual or mechanical chest percussion and postural drainage may be beneficial in patients producing $>25 \mathrm{~mL}$ sputum per day or with lobar atelectasis.

\section{A. Singh \\ Pulmonary and Critical Care Medicine, Christian Medical College and Hospital, Ludhiana, India.}

\section{STATEMENT OF INTEREST}

None declared.

\section{REFERENCES}

1 Celli BR, Barnes PJ. Exacerbations of chronic obstructive pulmonary disease Eur Respir J 2007; 29: 1224-1238.

2 Aubier M, Murciano D, Milic-Emili J, et al. Effects of the administration of $\mathrm{O}_{2}$ on ventilation and blood gases in patients with chronic obstructive pulmonary disease during acute respiratory failure Am Rev Respir Dis 1980; 122: 747-754.

3 Barr RG, Rowe BH, Camargo CA Jr. Methylxanthines for exacerbations of chronic obstructive pulmonary disease: meta-analysis of randomised trials BMJ 2003; 327: 643.

4 Kirsten DK, Wegner RE, Jörres RA, Magnussen H. Effects of theophylline withdrawal in severe chronic obstructive pulmonary disease Chest 1993; 104: 1101-1107.

5 Rabe KF, Hurd S, Anzueto A, et al. Global Strategy for the Diagnosis, Management, and Prevention of Chronic Obstructive Pulmonary Disease-2006 Update. Am J Respir Crit Care Med 2007; [Epub ahead of print PMID: 17507545].

DOI: $10.1183 / 09031936.00072207$ 